\title{
Characterization of Tyrosine Nitration and Cysteine Nitrosylation Modifications by Metastable Atom-Activation Dissociation Mass Spectrometry
}

\author{
Shannon L. Cook, Glen P. Jackson
}

Center for Intelligent Chemical Instrumentation, Department of Chemistry and Biochemistry, Ohio University, Athens, $\mathrm{OH}$ 45701-2979, USA

\begin{abstract}
The fragmentation behavior of nitrated and S-nitrosylated peptides were studied using collision induced dissociation (CID) and metastable atom-activated dissociation mass spectrometry (MAD-MS). Various charge states, such as 1+, 2+, 3+, 2-, of modified and unmodified peptides were exposed to a beam of high kinetic energy helium $(\mathrm{He})$ metastable atoms resulting in extensive backbone fragmentation with significant retention of the post-translation modifications (PTMs). Whereas the high electron affinity of the nitrotyrosine moiety quenches radical chemistry and fragmentation in electron capture dissociation (ECD) and electron transfer dissociation (ETD), MAD does produce numerous backbone cleavages in the vicinity of the modification. Fragment ions of nitrosylated cysteine modifications typically exhibit more abundant neutral losses than nitrated tyrosine modifications because of the extremely labile nature of the nitrosylated cysteine residues. However, compared with CID, MAD produced between $66 \%$ and $86 \%$ more fragment ions, which preserved the labile -NO modification. MAD was also able to differentiate $\mathrm{I} / \mathrm{L}$ residues in the modified peptides. MAD is able to induce radical ion chemistry even in the presence of strong radical traps and therefore offers unique advantages to ECD, ETD, and CID for determination of PTMs such as nitrated and Snitrosylated peptides.
\end{abstract}

Key words: Posttranslational modifications, PTMs, Nitration, Nitrosylation, Activation techniques, Fragmentation techniques, Electron transfer dissociation, ETD, Electron capture dissociation, ECD, Metastable atoms, Penning ionization, Peptide sequencing

\section{Introduction}

C lucidating how a PTM can alter a protein's structure and Eiological function is an integral part of proteomics. The

Electronic supplementary material The online version of this article (doi:10.1007/s13361-010-0041-4) contains supplementary material, which is available to authorized users.

Correspondence to: Glen P. Jackson; e-mail: jacksong@ohio.edu ability to identify and localize these modifications, in particular nitration and S-nitrosylation, can aid in biomarker discoveries for neurological diseases [1,2], cardiovascular diseases [3, 4], lung diseases [5, 6], and diabetes [7]. Tyrosine and cysteine amino acid residues are highly susceptible to oxidation by one or more forms of reactive nitrogen species such as nitric oxide radicals [8]. For example, reaction of a nitrogen dioxide radical with tyrosine can produce a covalently bound $-\mathrm{NO}_{2}$ to the tyrosine side chain thereby producing 3-nitrotyrosine [9]. Cysteine nitro- 
sylation can occur through a reaction with nitric oxide radicals resulting in the addition of $-\mathrm{NO}$ [10]. Developing rapid and accurate mass spectrometry (MS)-based methods for direct detection of both nitration and S-nitrosylation can aid in the understanding of how the reactive nitrogen species plays a role in certain diseases and can provide new diagnostic tools.

MS has become a leading tool in proteomics because of its ability to sequence peptides and proteins and characterize PTMs. The most widely used MS techniques for studying nitrotyrosine and nitrosylated cysteine PTMs in peptides and proteins are matrix assisted laser desorption/ionization timeof-flight MS (MALDI-TOF) and electrospray ionization (ESI) MS/MS [9]. UV-MALDI has been noted to lead to a high degree of photodegradation or in-source decay of nitrated or S-nitrosylated peptides, thereby rendering the modified peptides weak or absent $[9,11,12]$. The dissociation method traditionally employed in ESI MS/MS is CID, and CID tends to preferentially cleave side chain PTMs instead of the peptide backbone. The preference for side-chain cleavages leads to poor sequencing information and PTM characterization. Biotin-switching, in which the labile nitrosylated cysteines are derivatized to a more stable biotinylated cysteine, was developed to combat these issues [13]. However, the precise control of the chemical reactions has proven to be difficult and can result in false positives $[12,14]$. Methods such as precursor ion scanning of the nitrotyrosine immonium ions [15] and selected reaction monitoring combined with UV absorption [16] have both shown to be promising techniques to characterize nitrotyrosine when analyzing complex samples.

Alternative types of peptide dissociation methods that utilize radical chemistry have been recently introduced to provide both accurate sequencing and PTM information. ECD, first introduced in 1998 by McLafferty and coworkers, has proven to effectively fragment the peptide backbone in Fourier transform ion cyclotron resonance mass spectrometers (FT-ICR-MS) [17]. This method preferentially cleaves the more energetic peptide backbone $\mathrm{N}-\mathrm{C} \alpha$ bonds resulting in mainly c-/z-type ions, in contrast to the "slowheating" dissociation methods such as CID and IRMPD [18]. The latter activation methods tend to cleave the lower energy $\mathrm{C}-\mathrm{N}$ bonds and produce b-/y-type ions. ETD, introduced by Hunt and co-workers, uses ion-ion reactions to transfer electrons from a radical anion to polycations resulting in ECD like fragmentation [19]. Successful PTM site determinations of phosphorylation [19, 20], sulfation [21, 22], and glycosylation [23-25], among others, have been reported for ECD and ETD. However, traditional ECD and ETD are not applicable to singly protonated or negatively charged precursor ions such as the more acidic peptides. Recently, new techniques have been developed to apply these two methods, NETD and niECD, to negative ions [26-28].

There have been only a few reports applying ECD and ETD to nitrated and S-nitrosylated peptides. It has been shown that in ECD and ETD, backbone fragmentation is completely inhibited in peptides containing specific tags with electron affinities (EA) larger than $1 \mathrm{eV}$. Such tags are termed electron predators, and examples include 3-nitrobenzyl and 3,5-dinitrobenzyl moieties [29]. Beauchamp and co-workers proposed that the propagation of the captured electron can relax through space or through bond $(\pi)$ to high EA predators (tags), which competes with the traditional electron transfer to the amide $\pi^{*}$ orbital. A hydrogen atom from a separate site on the peptide can then be transferred to the electron predator radicals due to their high $\mathrm{H}$-atom affinity. Tureček, on the other hand, proposes intermolecular $\mathrm{H}$-atom transfer from the aminoketyl radical of the chargereduced species to the nitrobenzyl moieties instead of direct electron sequestering [30]. In this mechanism, backbone fragmentation is inhibited based on the high H-atom affinity of the nitrobenzyl groups. Regardless of the exact mechanism, the presence of nitrobenzyl moieties inhibits traditional ECD and ETD N-C $\alpha$ backbone cleavage. Recently, nitrotyrosine residues have been shown to hinder backbone cleavage during ECD because of the electron predator or $\mathrm{H}$ atom trap effect [31]. These results demonstrate that ECD is not the method of choice to characterize nitrated tyrosine residues of $2+$ and $3+$ charge states of peptides [31]. However, top-down analysis of multiply charged, larger nitrotyrosine-containing proteins using ECD has shown promise when combined with other "slow heating" methods to identify PTM sites [32].

Few studies have concentrated on direct MS detection of cysteine nitrosylation, probably due to its labile nature. Snitrosylated bovine insulin was explored with ETD resulting in only a select number of backbone cleavages and fragment ions retaining the modification, thereby hindering site determination [22]. The major dissociation pathway observed in ECD was charge reduction (electron transfer without fragmentation) with and without losses of the NO [22]. ETD was therefore unable to identify the location of the PTM.

Recently, a new type of dissociation method using metastable atoms as the electron vehicle or potential energy source has been explored in RF ion trapping instruments, which we term metastable atom-activated dissociation (MAD). The interaction of isolated precursor ions with a high kinetic energy beam of argon or helium metastable atoms produces a high degree of peptide backbone cleavages resulting in a-, b-, c-, $\mathrm{x}-, \mathrm{y}-$, and z-type ions while retaining PTMs [33]. To date, comprehensive dissociation has been demonstrated to fragment multiply charged cations and anions [33-35], 1+ cations [33, 36, 37], phosphorylated cations [33, 35, 37], disulfide bonds [35], to cleave the amide ring structure of proline [33] and to differentiate isoleucine from leucine $[33,36]$.

Unlike ECD and ETD, there is evidence for two competing dissociation mechanisms responsible for the type and degree of fragment ions observed in MAD. The first is Penning ionization, which has been well characterized with 
neutral precursor molecules and occurs when the potential energy of the metastable atom is greater than the ionization potential of the neutral [38] or biomolecular ion. It has been well documented that metastable atoms are attracted to regions of high electron density such as the lone pairs of electrons on carbonyl oxygen atoms. Penning ionization at these sites leads to the generation of radicals at the lone pair [39]. The second mechanism observed in MAD is a similar mechanism proposed for ECD and ETD and is referred to as charge reduction. The charge reduction mechanism occurs when an electron from the metastable atom is transferred to the polycation of interest. The specific electron capture mechanism in ECD and ETD of peptides and proteins is still in debate [40-43]. However, all mechanisms agree that the electron transfer process generates a radical bio-ion that can rearrange, propagate along the peptide backbone, and subsequently fragment.

In this work, we investigated the ability of He MAD to characterize nitrated and S-nitrosylated peptides. We conducted a comparison of MAD and CID on the 1+, 2+, 3+, and 2- charge states of two nitrated peptides, DRVnYIHPF and GPLEnYGFAKGPLAK, and two S-nitrosylated peptides, VFDARDnCRSAQ and EMFTYInCNHIK, as well as the respective unmodified peptides. S-nitrosylated peptides were extremely labile and often difficult to isolate. However, when combining the MAD fragmentation information from different precursor ion charge states, modification site location was achieved. We demonstrate that MAD is a viable alternative for the direct analysis of nitrated and Snitrosylated peptides and provides radical-like fragmentation where ETD and ECD fail to deliver. The unique chemistry and structural information obtained through MAD can complement CID, ETD, and ECD methods of analysis.

\section{Experimental}

\section{Instrumentation}

All experiments were performed on a modified Bruker EsquireLC QIT MS (Bruker Daltonics, Bremen, Germany) as described previously [33]. An Ion Tech FAB gun (P50 PSU; Teddington, UK) was used as the metastable atom source as reported elsewhere [33, 35]. A deflection electrode consisting of two flat-ended 4-40 screws mounted within a PEEK (polyether ether ketone) sleeve was mounted on the bottom of the FAB gun to prevent ions and free electrons from entering the trap. The electrodes were positioned $1 \mathrm{~cm}$ downstream of the exit orifice of the FAB gun, orthogonal to the FAB beam, with an inter-electrode spacing of $5 \mathrm{~mm}$. One electrode was grounded and the other was biased to $+800 \mathrm{~V}$ using a high voltage power supply (EL 03R 15 L; Glassman High Voltage Inc., High Bridge, NJ, USA). For pulsed operation of the FAB gun, the anode power supply was replaced with a $10 \mathrm{kV}$ high voltage amplifier (ANT 10B10; Matsusada Precision Inc., Shiga, Japan). A trigger was taken from the Bruker EsquireLC at pin 15 of connector
J522 and fed to a function/arbitrary waveform generator (33250A; Agilent, Santa Clara, CA, USA), which generated a square pulse with a set pulse width and delay time depending on precursor mass. Complete pulse operation and generation has been previously described [33]. The FAB gun was placed approximately $2 \mathrm{~cm}$ above a $4 \mathrm{~mm}$ hole in the ring electrode, which enabled the metastable atoms to traverse to the center of the QIT and interact with the isolated biomolecular ions of interest. Background ions were observed in both positive and negative modes due to Penning ionization of residual pump oils, which could be actively removed from the trap by employing a trapping voltage corresponding to a LMCO value above $\mathrm{m} / \mathrm{z} 200$ for positive mode and $\mathrm{m} / \mathrm{z} 300$ for negative mode. Before use each day, the FAB gun was turned on for 30 min to "burn" away residual contaminants such as pump oil. This helped decrease background ion signals.

\section{Preparation of Peptides}

The S-nitrosylated and non-nitrosylated forms of two endothelial nitric oxide synthase (eNOS) peptides (194204; 205-215) and non-nitrated angiotensin II were provided by Protea Biosciences Inc. (Morgantown, WV, USA). Nitrated GPLEnYGFAKGPLAK was purchased from Alta Bioscience (Birmingham, UK). Trimethylnitrate (TMN), AccuGENE Tris-Borate buffer, methanol (HPLC grade), and glacial acetic acid were purchased from Sigma-Aldrich (St. Louis, MO, USA). All peptides were reconstituted in a $1: 1$ mixture of methanol and water with either $1 \%$ acetic acid or ammonium hydroxide (depending on desired charge state) to provide solutions between 20 and $40 \mu \mathrm{M}$ of the individual peptides. Ultrahigh-purity helium and argon (Airgas, Parkersburg, WV, USA) were further purified on-line with a noble gas purifier (HP2; VICI, Houston, TX, USA). Angiotensin II was nitrated by incubating for $1 \mathrm{~h}$ at $37^{\circ} \mathrm{C}$

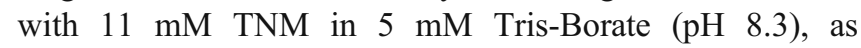
described by Lee et al. [44]. Samples were desalted by using $\mathrm{C}_{18}$ SpinTips Sample Prep Kit, using protocol 2 (Protea Biosciences Inc., Morgantown, WV, USA).

\section{Method}

All peptides were directly injected using an electronic syringe pump (BM-1000; Protea Bioscience Inc., Morgantown, WV, USA) at a flow rate of $200 \mu \mathrm{L} / \mathrm{h}$. Isolation windows varied between $\mathrm{m} / \mathrm{z} 1$ and 6 depending on the labile nature of the modified precursor ion. Ion accumulation was set to $15-25 \mathrm{~ms}$ to reach an ion target of 20,000. Precursor ion intensity ranged from $8 \times 10^{4}-4 \times 10^{5} \mathrm{AU}$ depending on peptide and precursor charge state. All fragment ion identifications and assignments were manually determined based on predicted fragmentation patterns and were within $\pm 0.8 \mathrm{~m} / \mathrm{z}$ of the expected product ions. Peaks were only assigned if the intensities were at least three times the signalto-noise ratio. The $2+$ and $3+$ ions were identified according 
to the expected $\mathrm{m} / \mathrm{z}$ value and the presence of an isotope envelope peak at $\mathrm{m} / z+0.5$ and $\mathrm{m} / z+0.3$, respectively.

\section{$C I D$}

All cationic and anionic peptides were fragmented using the "SmartFrag" option in the Bruker EsquireLS NT 4.5 software, which applied a sweeping collisional energy starting at $20 \%$ and ending at $150 \%$ of a set value. The fragmentation time was set to $20 \mathrm{MS}$ in all experiments. The collisional energy was set to $0.4-1.2 \mathrm{~V}$ depending on precursor mass and compound stability. CID MS/MS data was acquired in 1 min intervals, and consist of approximately 200 averaged spectra.

\section{$M A D$}

$1+, 2+, 3+$, and $2-$ precursor ions were exposed to a beam of high kinetic energy $\mathrm{He}$ metastable atoms with the FAB anode powered at $6 \mathrm{kV}$. A pulsed metastable atom beam was applied for 75-150 MS depending on the charge state of the precursor ion. The pressure in the vacuum chamber, outside the ion trap, was kept at 1.8 mbar (uncorrected) with helium leaking out of the trap and an additional 1.0 mbar (uncorrected) of the noble gas from the metastable atom source. MAD MS/MS spectra were acquired in $\sim 2$ min intervals and consist of between 300 and 450 averaged spectra. MAD MS/ MS data were background subtracted using a spectrum obtained with identical conditions as above, but with the ESI source off.

\section{Results and Discussion}

\section{Tyrosine Nitrated Peptides}

Figure 1(a-f) show MAD-MS spectra of the $1+, 2+$, and $3+$ charge states of nitrated angiotensin II (DRVnYIHPF) and the synthetic peptide, GPLEnYGFAKGPLAK. A lower case ' $n$ ' indicates the amino acid directly to the right is modified. Both peptides had a precursor ion mass increase of $45 \mathrm{Da}$ relative to the unmodified peptides, confirming the addition of an $-\mathrm{NO}_{2}$ group. Peptide sequence inserts in Figure 1 omit those fragment ions that have undergone a neutral loss of the PTM modification.

Combining the fragmentation products for the $1+, 2+$, and $3+$ charge states of angiotensin II (Figure 1(a-c), respectively) a total of 26 distinct a-, b-, c-, x-, y-, and ztype fragment ions out of 42 possible backbone cleavages are observed. At least one backbone cleavage is observed between each amino acid residue for the $1+$ and $2+$ charge states resulting in complete sequence coverage. MAD of the $1+$ precursor ion (Figure 1(a) yielded 21 total fragment ions with seven $2+$ product ions and a dominant Penning ionized species, $[\mathrm{M}+\mathrm{H}]^{2+\bullet}$. The production of $2+$ product ions from $1+$ precursor ions is direct evidence for Penning ionization (PI) $[33,38]$ and is unique to MAD in comparison to CID,
ECD, and ETD. The small insert in Figure 1(a) is the isotopic distribution of the PI product ion species showing that the most intense peak is the $1+$ species. Figure 1(a) of the $1+$ precursor shows $8 \mathrm{C}-\mathrm{N}, 6 \mathrm{C}_{\alpha}-\mathrm{C}$, and only $2 \mathrm{~N}-\mathrm{C}_{\alpha}$ bond cleavages. The figure also shows that the nitration modification remains mostly intact during exposure to He metastable atoms, which enables PTM site determination. In total, seven different product ion-types undergo a neutral loss of the PTM modification (indicated by $*$ in the spectrum), however five of these seven ions are also observed with the modification intact. A neutral loss of $18 \mathrm{Da}\left(-\mathrm{H}_{2} \mathrm{O}\right)$ from both the $[\mathrm{M}+\mathrm{H}]^{2+\bullet}$ and the $\left[\mathrm{M}+\mathrm{H}-\mathrm{NO}_{2}\right]^{2+\bullet}$ species was observed.

Figure 1(b) is a MAD spectrum of the 2+ precursor ions. MAD resulted in 25 product ions and cleavage between every amino acid. Of note in Figure 1(b) is the neutral loss of a hydrogen radical from the charge-reduced ions, $[\mathrm{M}+2 \mathrm{H}]^{+\bullet}$, which is more abundant than the PI product species, $[\mathrm{M}+2 \mathrm{H}]^{3+\bullet}$. Again the most dominant fragmentation pathway was cleavage of the $\mathrm{C}-\mathrm{N}$ bonds, with nine total b-/y-type ions. However, a large number of a- and c-type ions were also observed. The neutral loss of $29 \mathrm{Da}$ from the side chain of the $\mathrm{z}_{4}$ ion produced the $\mathrm{w}_{4}$ ion and enables the definitive identification of an isoleucine residue instead of the more ambiguous, isobaric isoleucine residue. Isoleucine undergoes a neutral loss of $\mathrm{CH}_{2} \mathrm{CH}_{3}(29 \mathrm{Da})$, whereas leucine undergoes a neutral loss of $\cdot \mathrm{CH}\left(\mathrm{CH}_{3}\right)_{2}$ (43 Da) [45]. The majority of the product ions, 16 out of a possible 18 , contain the nitrated tyrosine modification. Neutral losses of $18 \mathrm{Da}\left(-\mathrm{H}_{2} \mathrm{O}\right)$ were observed from the $[\mathrm{M}+2 \mathrm{H}]^{+}$species and the precursor ion, $[\mathrm{M}+2 \mathrm{H}]^{2+}$, respectively. Figure 1(c) is a fragmentation spectrum of the $3+$ precursor ions using MAD. In total, only 12 product ions were observed and were mostly $\mathrm{C}-\mathrm{N}$ bond cleavages. The most intense product ion peaks observed are the $[\mathrm{M}+2 \mathrm{H}]^{2+}$ species, presumably from a hydrogen radical loss from the charge-reduced product ion, and the neutral loss of $\mathrm{H}_{2} \mathrm{O}$ from the $[\mathrm{M}+3 \mathrm{H}]^{2+\bullet}$ species. The minimal amount of backbone cleavages in the electron transfer from the metastable atom to the polyprotonated precursor is consistent with observations in ETD, although MAD is inhibited to a smaller extent than ETD [31]. The nitration modification was retained in all cases when dissociating the $3+$ precursor. The hydrogen radical loss from the charge-reduced species, $[\mathrm{M}+3 \mathrm{H}]^{2+\bullet}$, is the most intense peak within the charge-reduced isotope envelope in Figure 1(c); in fact this is the case for all positively charged peptides in this study. However, when evaluating the isotopic distribution of the charge-reduced species, electron transfer is still apparent by the observation of the $[\mathrm{M}+3 \mathrm{H}]^{2+\bullet}$ peak (Figure 1(c)). A mass isolation window of $m / z 1$ was possible in this case because of the stabile nature of the nitrated peptides studied. The smaller isolation window reduced the contribution of ${ }^{13} \mathrm{C}$ to the intensity of the charge-reduced peak. Hydrogen radical neutral loss from the charge-reduced species is also noted in ECD [31, 46]. In each of the three charge states studied, the nitration modification is unambiguously identified to be bound to the fourth amino acid residue. 
(a)
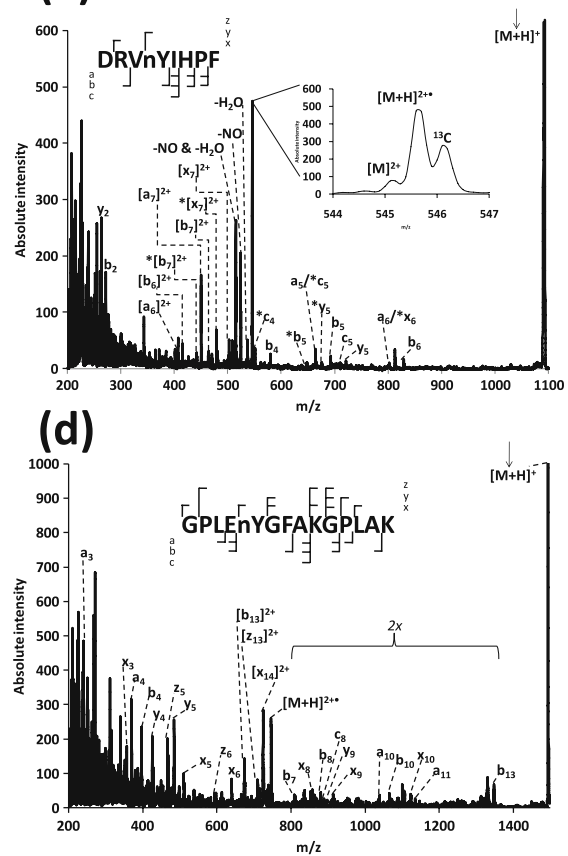

(b)

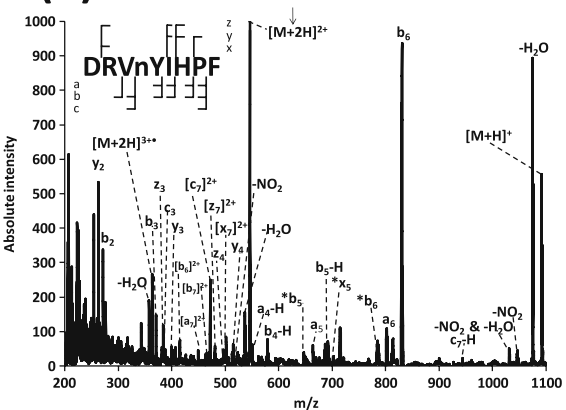

(e)

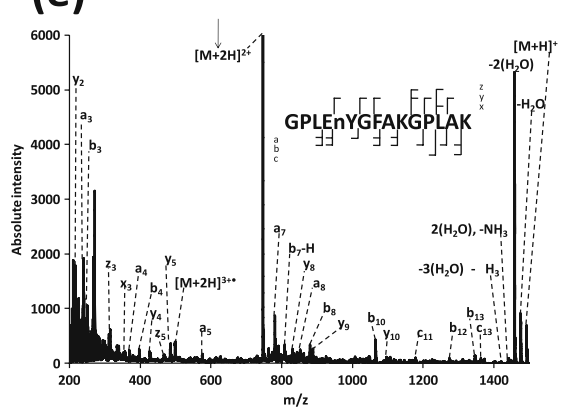

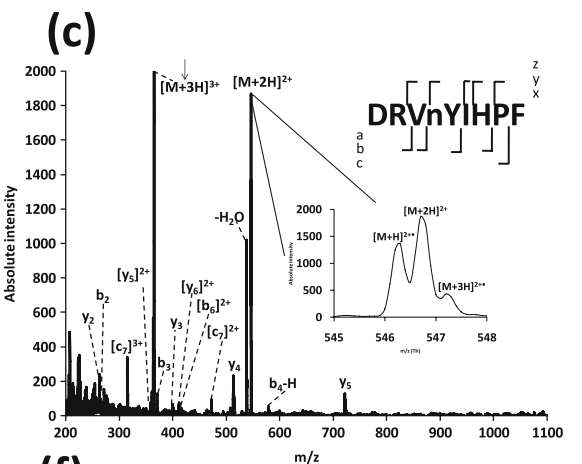

(f)

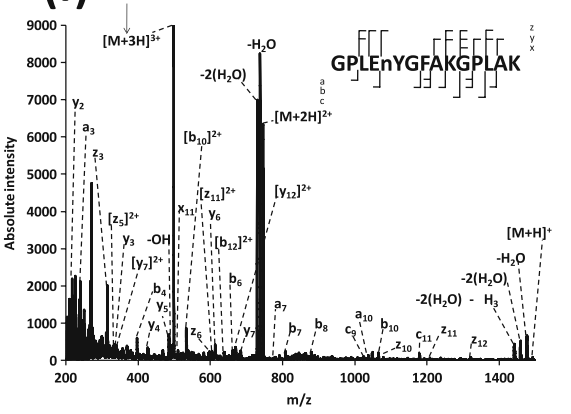

Figure 1. He MAD spectra of nitrated angiotensin II (DRVnYIHPF): (a) $[\mathrm{M}+\mathrm{H}]^{+}$, (b) $[\mathrm{M}+2 \mathrm{H}]^{2+}$, (c) $[\mathrm{M}+3 \mathrm{H}]^{3+}$, and He MAD spectra of nitrated GPLEnYGFAKGPLAK: (d) $[\mathrm{M}+\mathrm{H}]^{+},(\mathbf{e})[\mathrm{M}+2 \mathrm{H}]^{2+},(\mathrm{f})[\mathrm{M}+3 \mathrm{H}]^{3+}$. The precursor is indicated by an arrow and the neutral loss of the modification is indicated by an asterisk. Fragments that do not retain the modification are omitted from the peptides sequence inserts

Figure $1(\mathrm{~d}-\mathrm{f})$ show comprehensive backbone cleavage for the $1+, 2+$, and $3+$ precursor ions of the synthetic peptide GPLEnYGFAKGPLAK. A total of 42 distinct a-, b-, c-, x-, $\mathrm{y}$-, and z-type fragment ions, out of a total of 78, are produced and complete peptide sequencing is achieved when combining different charge state product ions. MAD of the $1+$ precursor ion (Figure 1(d)) produced 25 product ions as well as three 2+ product ions and the PI product ion species, $[\mathrm{M}+\mathrm{H}]^{2+\bullet}$. The major fragmentation pathway tends to be the $\mathrm{C}_{\alpha}-\mathrm{C}$ bonds with 11 total a-/x-type ions. An additional nine $\mathrm{C}-\mathrm{N}$ bond cleavages and four $\mathrm{N}-\mathrm{C}_{\alpha}$ bond cleavages were also observed. The observation of the $\mathrm{w}_{3}$ ion, a neutral loss of $43 \mathrm{Da}$ from the $\mathrm{z}_{3}$ ion, allows for the differentiation of leucine from isoleucine at position 12. Out of 10 possible fragment ions containing the nitrated tyrosine, all 10 retained the modification thereby allowing for PTM site determination. The most notable feature in the MAD spectrum of the $2+$ species shown in Figure 1(e) are the neutral losses from the charge-reduced species $[\mathrm{M}+2 \mathrm{H}]^{+\bullet}$. The four neutral losses are $18,36,53$, and $70 \mathrm{Da}$, which correspond to $\left[\mathrm{M}+2 \mathrm{H}-\mathrm{H}_{2} \mathrm{O}\right]^{+\bullet},\left[\mathrm{M}+2 \mathrm{H}-2\left(\mathrm{H}_{2} \mathrm{O}\right)\right]^{+\bullet},\left[\mathrm{M}+2 \mathrm{H}-2\left(\mathrm{H}_{2} \mathrm{O}\right)\right.$ $\left.-\mathrm{NH}_{3}\right]^{+\bullet}$, and $\left[\mathrm{M}+2 \mathrm{H}-3\left(\mathrm{H}_{2} \mathrm{O}\right)-\mathrm{NH}_{3}\right]^{+\bullet}$, respectively. The first two ions (loss of 18 and $36 \mathrm{Da}$ ) are more abundant than the $[\mathrm{M}+\mathrm{H}]^{+}$species which corresponds to a neutral loss of a hydrogen radical from the charge-reduced species, $[\mathrm{M}+2 \mathrm{H}]^{+\bullet}$. Similar neutral losses are also observed when dissociating the same nitrated peptide through ECD [31]. For MAD of the $2+$ precursor, a total of 24 product ions are produced with backbone cleavage between every amino acid residue with the exception of the first two, as illustrated in Figure 1(e). Again, the $w_{3}$ ion was observed, thereby enabling the 12th residue to be confirmed to be leucine. Similar to the 1+ precursor for this peptide (Figure 1(d)), no neutral losses associated with the loss of the nitrated PTM were observed and 11 fragment ions containing the nitration modification were observed. The major fragmentation pathway observed was cleavage of the $\mathrm{C}-\mathrm{N}$ bonds, producing $13 \mathrm{~b}-/ \mathrm{y}$-type ions.

MAD of the $3+$ species, Figure 1(f), produced 28 different product ions and two charge-reduced species, $[\mathrm{M}+3 \mathrm{H}]^{2+\bullet}$ and $[\mathrm{M}+2 \mathrm{H}]^{+\bullet}$. The $[\mathrm{M}+2 \mathrm{H}]^{+\bullet}$ product presumably results from two subsequent charge reduction reactions. The most intense peaks within the charge-reduced isotopic distributions correspond to the neutral loss of a hydrogen radical producing the $[\mathrm{M}+2 \mathrm{H}]^{2+}$ and $[\mathrm{M}+\mathrm{H}]^{+}$species. Again, neutral losses of 18 and $36 \mathrm{Da}$ were observed for both the $[\mathrm{M}+3 \mathrm{H}]^{2+\bullet}$ and $[\mathrm{M}+2 \mathrm{H}]^{+\bullet}$ species and a neutral loss of $53 \mathrm{Da}$ from the $[\mathrm{M}+2 \mathrm{H}]^{+\cdot}$ species. No neutral losses of the modification were observed, so 13 different PTMcontaining fragment ions were available for nitration site determination. The $\mathrm{w}_{3}$ ion is again observed, thereby enabling the 12th residue to be confirmed to be leucine. The majority of the backbone cleavages produced $b-/ y-$ type ions as similarly noted for MAD of the $2+$ species. Again, using MAD, characterization of the nitration modification was unambiguously assigned to the 5th amino acid, tyrosine. 


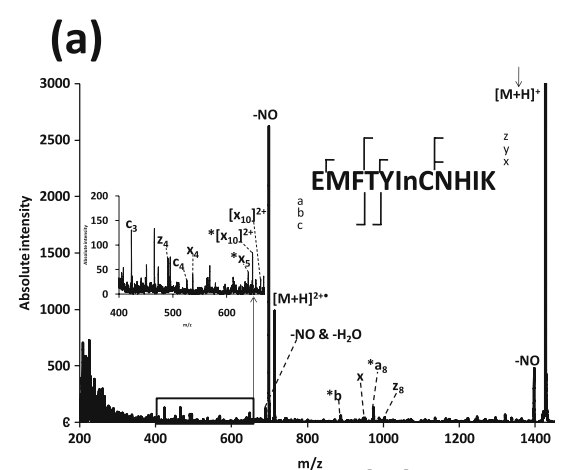

(d)

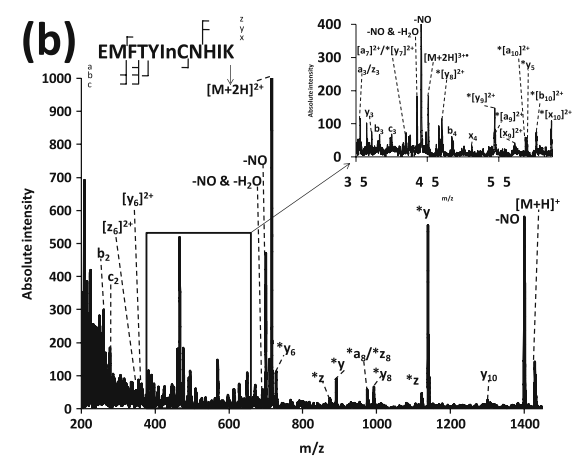

(e)

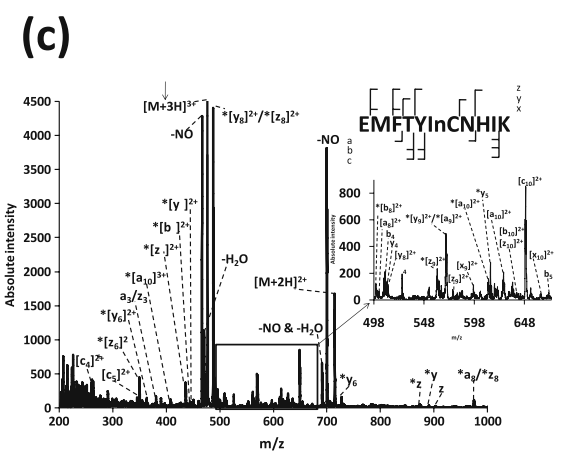

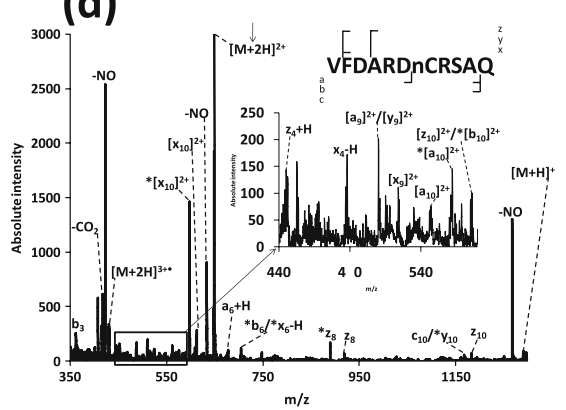

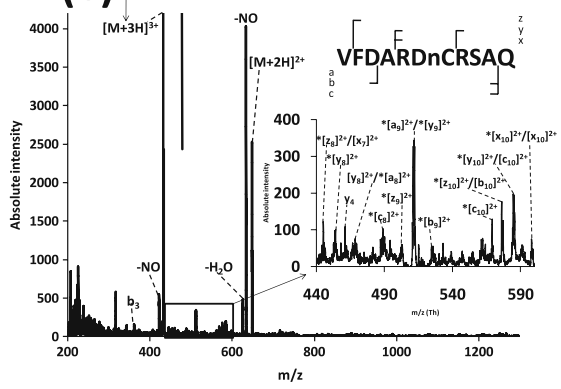

Figure 2. He MAD spectra of S-nitrosylated EMFTYInCNHIK: (a) $[\mathrm{M}+\mathrm{H}]^{+}$, (b) $[\mathrm{M}+2 \mathrm{H}]^{2+}$, (c) $[\mathrm{M}+3 \mathrm{H}]^{3+}$, and He MAD spectra of S-nitrosylated VFDARDnCRSAQ: (d) $[\mathrm{M}+2 \mathrm{H}]^{2+},(\mathbf{e})[\mathrm{M}+3 \mathrm{H}]^{3+}$. The precursor is indicated by an arrow and the neutral loss of the modification is indicated by an asterisk. Fragments that do not retain the modification are omitted from the peptides sequence inserts

\section{Cysteine Nitrosylated Peptides}

Figure 2(a-e) show MAD spectra of the $1+, 2+$, and $3+$ charge states of the S-nitrosylated peptide EMFTYInCNHIK (205215 of eNOS) and the $2+$ and $3+$ charge states of the Snitrosylated peptide VFDARDnCRSAQ (194-204 of eNOS). Isolation of the latter $1+$ peptide was not possible because of the labile nature of this PTM. The precursor mass of each of the peptides had an increase of $29 \mathrm{Da}$ relative to the unmodified peptides, confirming the addition of an -NO group. Again, the fragments with a neutral loss of the PTM modification were omitted from the peptide sequence inserts in Figure 2. Due to the extremely labile nature of the S-nitrosylation [47, 48], more gentle MS parameters and wider $m / z$ windows of 5-6 were required to isolate the precursor ions of the modified peptides. A higher percentage of S-nitrosylated neutral losses (30 Da) were detected relative to nitrated tyrosine containing peptides. The disruption of the S-NO bond has been observed to easily break under the most modest gas phase conditions [47].

When combining the product ions observed for the $1+, 2+$, and $3+$ charge states of the EMFTYInCNHIK peptide, MAD produced 37 , out of a possible 60 , distinct fragment ions (Figure 2(a), (b), and (c)). MAD of the 1+ precursor, illustrated in Figure 2(a), produced 11 fragment ions and an intense PI product species, $[\mathrm{M}+\mathrm{H}]^{2+\bullet}$, with neutral losses of the $\mathrm{S}$ nitrosylation from both the precursor ion and the PI product ion. Forty five percent of the backbone cleavages in Figure 2(a) were between the $\mathrm{C}_{\alpha}-\mathrm{C}$ bonds producing a-/x-type ions and $36 \%$ cleaved the $\mathrm{N}-\mathrm{C}_{\alpha}$ bond (c-/z-type ions). Of the six detected fragments that contained the modified cysteine residue, only three retained the S-nitrosylation group. Snitrosylation PTM site determination was therefore difficult or unambiguous with the $[\mathrm{M}+\mathrm{H}]^{+}$precursor. More comprehensive dissociation was achieved for the $2+$ precursor of the peptide (Figure 2(b)), producing 30 product ion types. However, 16 of the 19 fragment ions that could potentially give modification site information did not retain the Snitrosylation, thereby hindering PTM location. For MAD of the 2+ precursor (Figure 2(b)), complete peptide sequencing was achieved but the site of the PTM could not be unambiguously assigned. For the $2+$ precursor $37 \%$ of the fragment ions cleaved the $\mathrm{C}-\mathrm{N}$ bonds, with the majority being y-type ions. $\mathrm{N}-\mathrm{C}_{\alpha}$ and $\mathrm{C}_{\alpha}-\mathrm{C}$ bond cleavages are equally abundant at about $31 \%$ each. MAD of the $3+$ precursor ion also achieved complete sequencing information by producing 35 different product ions (including those which lost the Snitrosylation) as shown in Figure 2(c). In contrast to the dissociation of the $1+$ and $2+$ species, 10 different product ions retained the labile S-nitrosylation, thereby successfully determining the modification site on the cysteine as opposed to the tyrosine or threonine residues. A larger percentage of product ions retain the $\mathrm{C}$-terminus than the $\mathrm{N}$-terminus because of the two basic amino acid residues at the $\mathrm{C}$-terminus.

When combining the dissociation of both the $2+$ and $3+$ precursors of the VFDARRnCRSAQ peptide (Figure 2(d) and 2(e), at least one cleavage between each amino acid is observed, resulting in 21 distinct product ions in total. Cleavage of the $\mathrm{C}_{\alpha}-\mathrm{C}$ bond is the main backbone fragmentation observed when dissociating the $2+$ species (Figure 2 (d)) with nine a-/x-type ions or $42 \%$ of the total product 
ions. The main dissociation pathway observed is the neutral loss of $30 \mathrm{Da}$ from both the PI, $[\mathrm{M}+2 \mathrm{H}]^{3+\bullet}$, and the $[\mathrm{M}+2 \mathrm{H}]^{+} \cdot$ species, corresponding to the loss of NO from the modification site. Figure 2(e) shows the dissociation of the $3+$ species with 19 evenly distributed backbone cleavages. The two main peaks are the $[\mathrm{M}+2 \mathrm{H}]^{2+}$ species (the charge-reduced species with a hydrogen radical loss) and the neutral loss of the NO from the $[\mathrm{M}+3 \mathrm{H}]^{2+\bullet}$ species. For the $2+$ and $3+$ precursor ions, less than half of the product ions containing the nitrosylated cysteine residue retained the modification.

\section{Effect of Modification on Peptide Backbone Cleavage}

There is evidence that PTMs can have an adverse effect on the fragmentation efficiency of some electron-induced dissociation methods. Cooper and Creese show that phosphorylation modifications can interact with basic residues decreasing the amount of ECD backbone cleavages in 2+ species [49]. Therefore, determining how a certain modification affects fragmentation efficiencies and type of fragment ions observed needs to be further explored. Jones et al. provide evidence that ECD of nitrotyrosine-containing peptides severely inhibits $\mathrm{N}-\mathrm{C} \alpha$ backbone cleavages [31]. In fact, for $2+$ species, little backbone dissociation-except for small neutral losses from the charge-reduced species - is observed. More cleavages are noted for ECD of the 3+ species, most likely due to columbic repulsion extending the peptide conformation when not in close proximity to the modification [31]. This phenomenon is explained in two separate studies by Sohn et al. and Tureček, which have shown that ECD and ETD backbone fragmentation is (a)

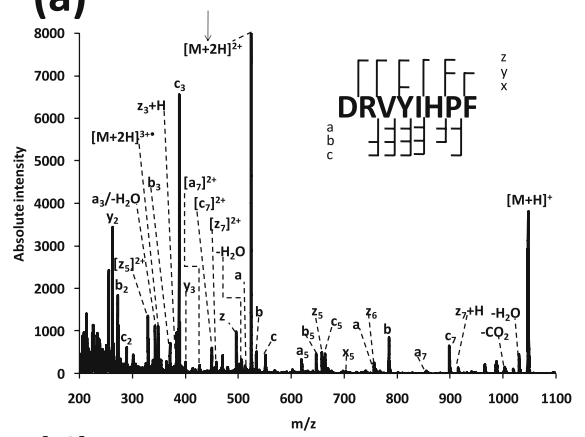

(d)
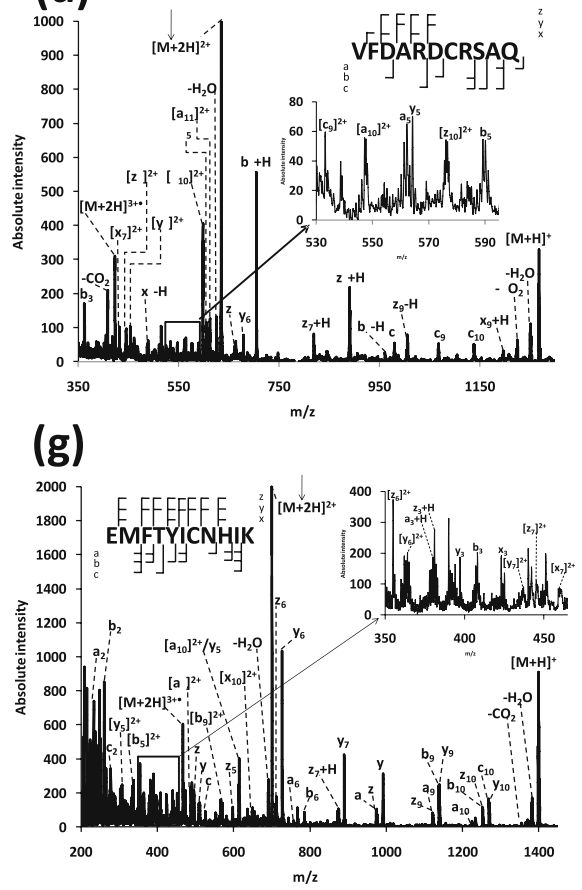

(b)

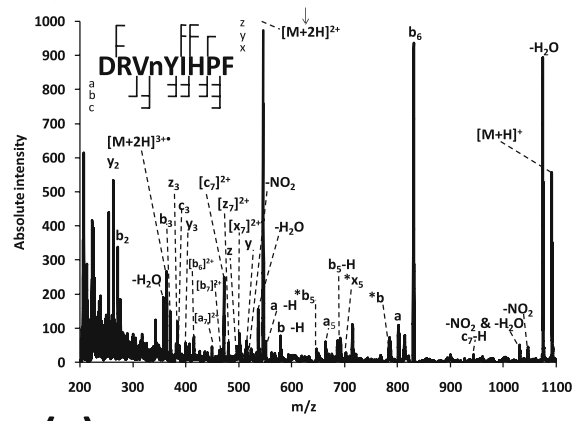

(e)
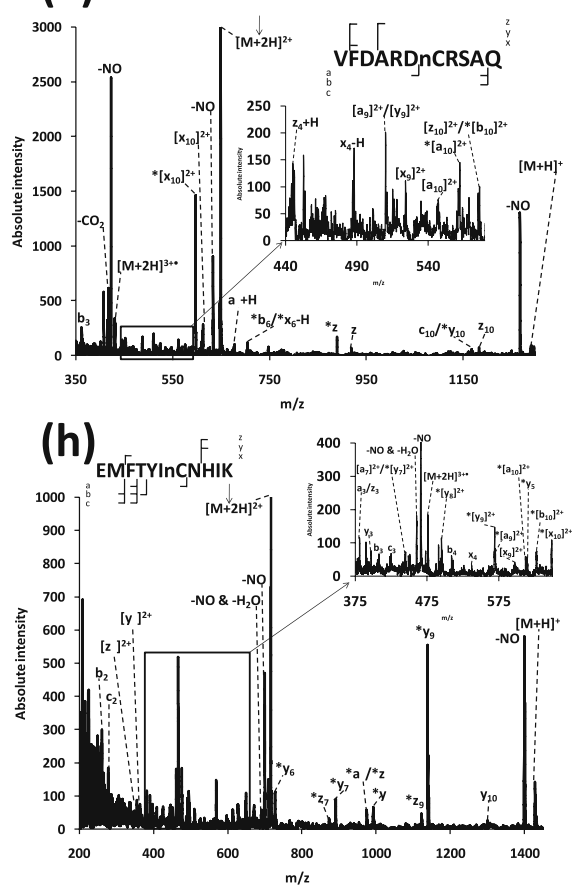

(c)

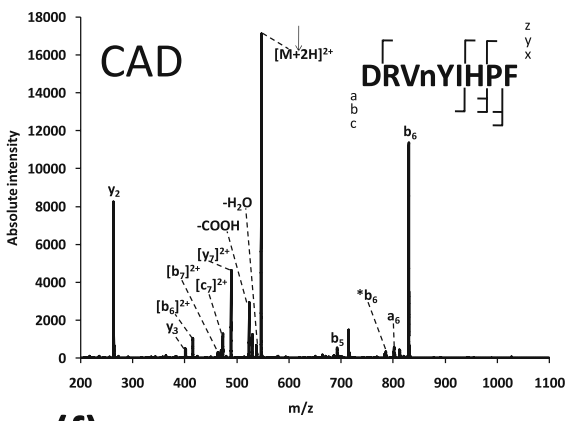

(f)

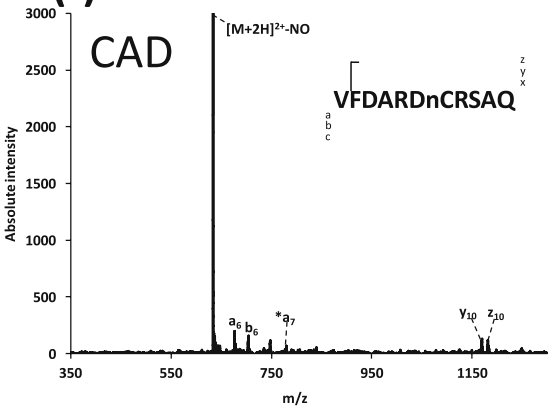

(i)

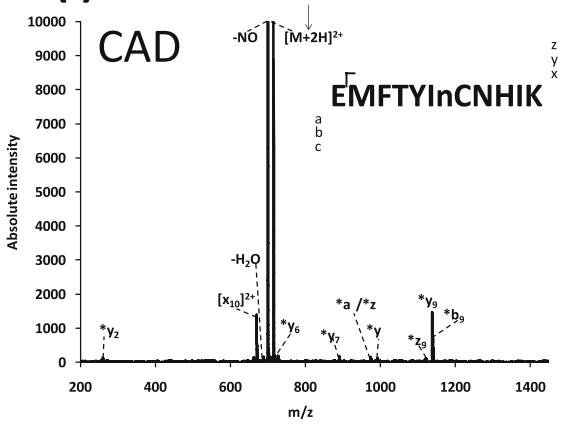

Figure 3. Comparison of the 2+ charged peptides: (a) MAD of non-nitrated DRVYIHPF, (b) MAD of nitrated DRVnYIHPF, (c) CID of nitrated DRVnYIHPF, (d) MAD of non-nitrosylated VFDARDCRSAQ, (e) MAD of S-nitrosylated VFDARDnCRSAQ, (f) CID of S-nitrosylated VFDARDnCRSAQ, (g) MAD of non-nitrosylated EMFTYICNHIK, (h) MAD of S-nitrosylated EMFTYInCNHIK, and (i) CID of S-nitrosylated EMFTYInCNHIK. The precursor is indicated by an arrow and the neutral loss of the modification is indicated by an asterisk. Fragments that do not retain the modification are omitted from the peptides sequence inserts 
completely inhibited when high EA $(>1 \mathrm{eV})$ nitrobenzyl moieties are present $[29,30]$. S-nitrosylation has also been shown to hinder the efficiency of ETD. ETD of S-nitrosylated insulin chain B was investigated by Mikesh et al. with very little backbone cleavage and PTM retainment observed [22]. Mikesh et al. concluded that the neutral loss of the NO from the charge-reduced species could act as its own proton transfer reagent, which ultimately decreases fragmentation yields.

Comparison of MAD and CID spectra of the nitrated and S-nitrosylated peptides and their unmodified equivalents in the $2+$ charge state are shown in Figure 3. MAD of the modified peptides produced enough dissociation to confer complete sequencing information, which has not been demonstrated for ECD and ETD. Comparing the amount of backbone cleavages observed with MAD and CID (see Supplemental Figure 1 and Supplemental Table 1), we note that CID alone is unable to obtain enough information to sequence the peptides and determine unambiguously the modification site locations. In fact, MAD produces almost two times more fragment ion types than CID that contain modification information. Figure 4 and Supplemental Table 2 compares the total number and types of ions for the spectra in Figure 3 produced for the $2+$ charge state of the unmodified and modified peptides. We observe a slight decrease in the number of backbone cleavage types when either modification is present (nitrosylated cysteine or nitrated tyrosine), with reductions between $5 \%$ and $42 \%$. Nonetheless, due to the ample dissociation of the modified peptides, these reductions do not undermine the ability to sequence the peptides independent of the PTM.
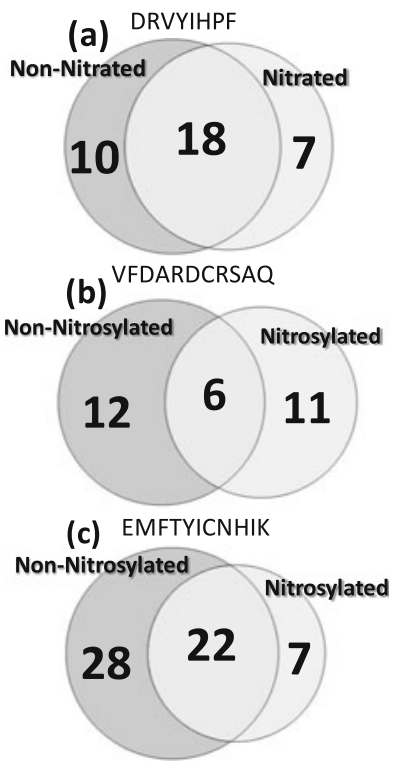

Figure 4. Venn diagrams comparing the number of fragmentation ion types produced after He MAD of the modified and unmodified peptides: (a) $[\mathrm{DRVYIHPF}+2 \mathrm{H}]^{2+}$, (b) $[\text { VFDARDCRSAQ }+2 \mathrm{H}]^{2+}$, and (c) $[\text { EMFTYICNHIK }+2 \mathrm{H}]^{2+}$
A direct comparison of MAD of the non-nitrated and nitrated species of the peptide GPLEYGFAKGPLAK was unattainable; however, we are still able to make some conclusions based on the MAD spectra of the nitrated form of this peptide species (Figure 1(d), (e), and (f)). Regardless of precursor charge state, extensive backbone cleavage is observed, including cleavage in and around the vicinity of the modification. When taking into account those fragments that undergo a neutral loss of the modification, all of the modified peptides studied contain at least two and as many as five backbone cleavage ion types directly adjacent to the modified residue. In contrast, fragmentation is inhibited near the site of nitration or S- nitrosylation in ECD and ETD [22, 31]. MAD fragmentation appears to not suffer the same inhibitions as ECD and ETD. There are two possible explanations for this contrasting behavior between MAD and ETD/ECD. The first explanation relates to the unique nature of metastable atom chemistry. Metastable atoms at the molecular level behave like positive ions and are known to be attracted to regions of high electron density or polar groups [50, 51]. In MAD, radicals can be directly generated anywhere along the peptide backbone where there is a polar group or lone pair of electrons, such as carbonyl oxygen atoms [33]. In ECD and ETD, radical migration must instead occur from original sites of protonation through long-range interactions with the carbonyl oxygen atoms along the backbone producing aminoketyl radicals. Whether the radical or hydrogen atoms are transferred first in ETD and ECD, these techniques are apparently more easily hindered by high electron- or hydrogen-affinity groups than MAD [30].

The second explanation for the difference between MAD and ETD/ECD fragmentation behavior may be due to high levels of secondary reactions in MAD. It was shown in our previous work that longer exposure times and more energetic He metastable atom exposure causes an increase in the relative abundance of low mass ions at the expense of high mass ions, most likely due to secondary reactions [33]. Although primary metastable atom reactions with the oxygen atom lone pairs of the $-\mathrm{NO}$ or $-\mathrm{NO}_{2}$ modifications could result in radical sequestering without fragmentation, a second metastable atom interaction with the same peptide at a different location could induce the observed dissociation.

Figure 4 and Supplemental Table 2 compare the different amount and types of fragment ions produced for the modified and unmodified peptides DRVYIHPF, VFDARDCRSAQ, and EMFTYICNHIK after He MAD exposure. Even though, in Figure 3, we observe backbone cleavage adjacent to the modified residues, a greater abundance of these types of cleavages are observed with the unmodified peptides. This is especially noted in Figure 4(a) and (c), which have the greater reduction of overall cleavages. These two observations may suggest that additional sites of lone pairs of electrons, such as those found on the $-\mathrm{NO}$ or $-\mathrm{NO}_{2}$ groups of the PTMs, in fact compete for the initial metastable atom interaction. 
(a)

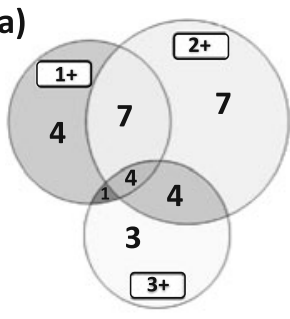

DRVnYIHPF (b)

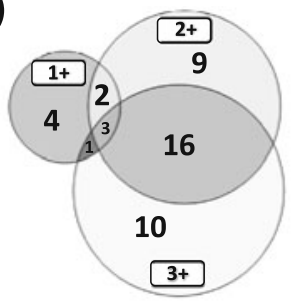

EMFTYInCNHIK (c)

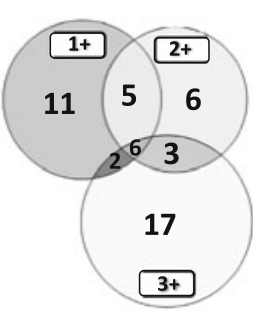

GPLEnYGFAKGPLAK

Figure 5. Venn diagrams comparing the number of fragment ion types produced by He MAD of the 1+, 2+, and 3+ charge states of the modified peptides: (a) DRVnYIHPF, (b) EMFTYInCNHIK, and (c) GPLEnYGFAKGPLAK
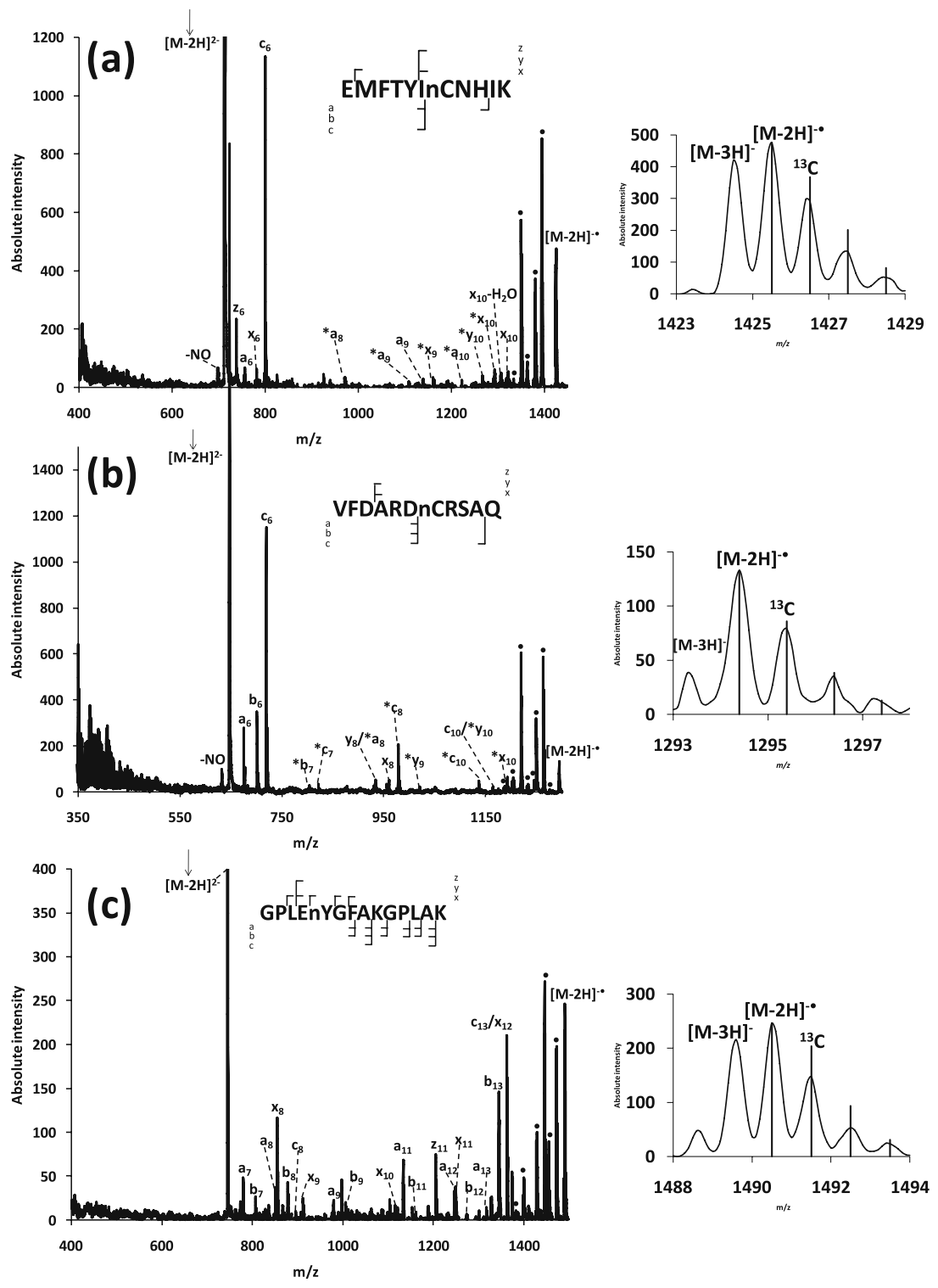

Figure 6. He MAD spectra of doubly-deprotonated S-nitrosylated: (a) EMFTYInCNHIK, (b) VFDARDnCRSAQ, and (c) GPLEnYGFAKGPLAK. The small inserts compare the actual and expected (vertical lines) isotopic distribution. The precursor is indicated by an arrow, neutral losses from the charge-reduced species are indicated by a dot, and the neutral loss of modification is indicated by an asterisk. Fragments that do not retain the modification are omitted from the peptides sequence inserts 
One overall trend observed for the three peptides in Figure 3 is that MAD of the non-modified peptides produced a higher percentage of $\mathrm{N}-\mathrm{C}_{\alpha}$ backbone cleavages compared to the modified (nitrated and S-nitrosylated combined) peptides. The modified peptides typically produced higher percentages of $\mathrm{C}_{\alpha}-\mathrm{C}$ and $\mathrm{C}-\mathrm{N}$ bond cleavages. A comprehensive analysis of a larger pool of peptides with varying types of modifications will need to be assessed before confirming trends in fragmentation behavior in MAD.

\section{Effect of Charge State on Peptide Backbone Cleavage}

The amount and type of backbone cleavages observed through MAD of the $1+, 2+$, and $3+$ charge states of the modified peptides, DRVnYIHPF, GPLEnYGFAKGPLAK, and EMFTYInCNHIK, and the 2+ and 3+ charge state of VFDARDnCRSAQ are compared in Figure 5 and Supplemental Table 3. The most striking observation is the vast difference in product ion types observed from the different precursor ion charge states. When comparing the three different charge states examined for a given peptide, only $13 \%, 6 \%$, and 16\% (Figure 5(a), (b), and (c)), respectively) of the total product ions observed are common to all charge states. This leads us to infer that the types of fragment ions produced by MAD are highly dependent on the charge state. There are at least three reasons for the differences in fragmentation types observed for MAD of the same peptide in different charge states. (1) A difference in mechanism, e.g., electron capture versus Penning ionization; (2) a difference in degree, e.g., electron capture of the $3+$ precursor is more exothermic than electron capture of the $2+$ precursor; or (3) a difference in the conformation of the peptide prior to interaction with the metastable atoms.

There is no observable trend between the precursor ion charge state and the product ion types observed in Figure 5. For example, MAD of the $3+$ species of angiotensin II and the $1+$ species of EMFTYInCNHIK produced the fewest fragment ion types of the three charge states observed for the specific peptide (Figure 5(a) and (b)), respectively). However, it was the $2+$ precursor species that produced the fewest fragment types for the peptide GPLEnYGFAKGPLAK (Figure 5(c)). For the three peptides studied, the 3+ precursor ions tend to produce more c-/z-type ions, whereas the $1+$ precursors tend to produce more a-/x-type ions. The $2+$ precursor ions typically produce more b-/y-type ions. These trends have not been validated against a larger database of precursor ions.

\section{S-Nitrosylated and Nitrated Peptide Anions}

Figure 6 shows the He MAD spectra of three peptides with a 2- charge state; two contain a S-nitrosylated modification (Figure 6(a) and (b)) and one contains a nitrated modification (Figure 6(c)). In all cases, the most abundant dissociation channels are neutral losses from the charge-reduced species including $\mathrm{H}_{2} \mathrm{O}(18 \mathrm{Da}), \mathrm{CO}_{2}(44 \mathrm{Da})$, and either $\mathrm{NO}$ or $\mathrm{NO}_{2}$ (30 or $46 \mathrm{Da}$, respectively). All the neutral losses observed from the charge-reduced species for the three peptides are listed in Table 1 and are indicated with a dot $(\bullet)$ within the spectra in Figure 6. Water and carbon dioxide groups are common neutral losses observed in other electron-induced dissociation methods on peptide anions, such as electron detachment dissociation (EDD) $[52,53]$ and negative electron transfer dissociation (nETD) [26, 54]. When dissociating protonated ions with MAD, the neutral loss of a hydrogen radical from the charge-reduced species is usually more abundant than the charge-reduced product ion. Deprotonated peptides also show signs of significant hydrogen radical loss, although not quite as abundant as when fragmenting cationic precursor ions. When comparing the ${ }^{13}$ $\mathrm{C}$ envelope to the expected envelope (Figure 6(a-c)), neutral losses of hydrogen radicals are still apparent. Figure 6(a) and (b) show the He MAD spectra of two S-nitrosylated peptides, both containing a modification on the 7th residue. A variety of ion types are observed for each peptide, with a majority of a-/x-type ions for the peptide in Figure 6(a) and a majority of c- and y-type ions in Figure 6(b). In both cases, $70 \%$ of information required for sequencing is obtained through the production of 10 (Figure 6(a)) and 13 (Figure 6 (b)) distinct fragment ions, including a modification retainment percentage of $50 \%$ and $43 \%$, respectively. In these two cases, the modification site can be unambiguously identified.

Figure 6(c) shows the MAD spectrum observed for the 2precursors of the nitrated peptide GPLEnYGFAKGPLAK. Similar to the peptide in Figure 6(a,) a-, b-, and x-type ions are most common. Because of the more stable nature of the nitration modification for the peptide in $6 \mathrm{c}$, all fragment ions retain the modification and enable PTM site determination. Furthermore, no observable trend can be noted based on ion

Table 1. List of the neutral losses observed from the charge-reduced species, $[\mathrm{M}-2 \mathrm{H}]^{-}$, after He MAD of the $2-$ peptide ions

\begin{tabular}{|c|c|c|}
\hline$[\mathrm{M}-2 \mathrm{H}]^{2-}$ peptide ion & Neutral loss (Da) & Proposed loss \\
\hline EMFTYInCNHIK & $\begin{array}{l}-30 \\
-45 \\
-62 \\
-75 \\
-92 \\
-107\end{array}$ & $\begin{array}{l}-\mathrm{NO} \\
-\mathrm{CO}_{2},-\mathrm{H} \\
-\mathrm{CO}_{2},-\mathrm{H}_{2} \mathrm{O} \\
-\mathrm{NO},-\mathrm{CO}_{2},-\mathrm{H} \\
-\mathrm{NO},-\mathrm{CO}_{2},-\mathrm{H}_{2} \mathrm{O} \\
-\mathrm{SNO},-\mathrm{CO}_{2},-\mathrm{H}\end{array}$ \\
\hline VFDARDnCRSAQ & $\begin{array}{l}-18 \\
-30 \\
-45 \\
-49 \\
-62 \\
-75 \\
-92 \\
-107\end{array}$ & $\begin{array}{l}-\mathrm{H}_{2} \mathrm{O} \\
-\mathrm{NO} \\
-\mathrm{CO}_{2},-\mathrm{H} \\
-\mathrm{NO},-\mathrm{H}_{2} \mathrm{O},-\mathrm{H} \\
-\mathrm{CO}_{2},-\mathrm{H}_{2} \mathrm{O} \\
-\mathrm{NO},-\mathrm{CO}_{2},-\mathrm{H} \\
-\mathrm{NO},-\mathrm{CO}_{2},-\mathrm{H}_{2} \mathrm{O} \\
-\mathrm{SNO},-\mathrm{CO}_{2},-\mathrm{H}\end{array}$ \\
\hline GPLEnYGFAKGPLAK & $\begin{array}{l}-18 \\
-36 \\
-45 \\
-62 \\
-90 \\
-108\end{array}$ & $\begin{array}{l}-\mathrm{H}_{2} \mathrm{O} \\
-\mathrm{H}_{2} \mathrm{O},-\mathrm{H}_{2} \mathrm{O} \\
-\mathrm{CO}_{2},-\mathrm{H} \\
-\mathrm{CO}_{2},-\mathrm{H}_{2} \mathrm{O} \\
-\mathrm{CO}_{2},-\mathrm{NO}_{2} \\
-\mathrm{CO}_{2},-\mathrm{NO}_{2},-\mathrm{H}_{2} \mathrm{O}\end{array}$ \\
\hline
\end{tabular}

The neutral losses are indicated with a dot in the corresponding spectra 
types produced, in contrast to EDD and nETD, which preferentially produce a-/x-type ions. That the fragmentation of EMFTYInCNHIK and VFDARDnCRSAQ appear to be directly adjacent to the highly electronegative nitrosylated cysteine residues supports the proposed mechanism of energy transfer as Penning ionization [33-35]. The site of preferential fragmentation seems to correlate to the PTM site rather than to the sites of deprotonation.

\section{Conclusion}

Extensive backbone cleavage of both nitrated and S-nitrosylated peptides were obtained after exposure to a high kinetic energy beam of He metastable atoms. MAD is less sensitive than ECD and ETD to the presence of nitrotyrosine, which can act as an electron predator and inhibit fragmentation in the latter two techniques. Complete peptide sequencing and PTM location is obtained for the majority of the peptides studied regardless of charge state or ion polarity. Amino acid side-chain cleavages enable L/I differentiation in several cases. Peptides containing nitrosylated cysteine residues prove to be highly labile, thereby making isolation prior to tandem analysis more difficult in general. However, we demonstrate that by combining multiple spectra of different charge states, accurate PTM site location can be achieved using MAD. Because of the unique fragmentation pathways offered through metastable atom chemistry, MAD is a complementary alternative to collisional or other electron-induced fragmentation methods.

\section{Acknowledgement}

The authors acknowledge and thank Protea Biosciences for donation of the S-nitrosylated peptides, angiotensin II, C18 SpinTips, and the syringe pump. They thank Desmond Kaplan and Ralf Hartmer at Bruker Daltonics for useful instrumentation discussions. They also thank The Ohio State University and Kari Green-Church for the use of their Bruker EsquireLC QIT-MS. This work was funded through NSF BIO 0649757 and through an NSF CAREER Award, CHE 0745590.

\section{References}

1. Chung, K.K.K., David, K.K.: Emerging roles of nitric oxide in neurodegeneration. Nitric Oxide22, 290-295 (2010)

2. Reynolds, M.R., Berry, R.W., Binder, L.I.: Nitration in neurodegeneration: deciphering the "Hows" "nYs". Biochemistry46, 7325-7336 (2007)

3. Peluffo, G., Radi, R.: Biochemistry of protein tyrosine nitration in cardiovascular pathology. Cardiovasc. Res.75, 291-302 (2007)

4. Turko, I.V., Murad, F.: Protein nitration in cardiovascular diseases. Pharmacol. Rev.54, 619-634 (2002)

5. Sheffield, M., Mabry, S., Thibeault, D.W., Truog, W.E.: Pulmonary nitric oxide synthases and nitrotyrosine: findings during lung development and in chronic lung disease of prematurity. Pediatrics118, 1056-1064 (2006)

6. Sugiura, H., Kornaki, Y., Koarai, A., Lchinose, M.: Nitrative stress in refractory asthma. J. Allergy Clin. Immunol.121, 355-360 (2008)

7. Wang, X.L., Rainwater, D.L., Leone, A., Mahaney, M.C.: Effects of diabetes on plasma nitrotyrosine levels. Diabetic Med.21, 577-580 (2004)
8. Stadtman, E.R., Levine, R.L.: Free radical-mediated oxidation of free amino acids and amino acid residues in proteins. Amino Acids 25, 207218 (2003)

9. Abello, N., Kerstjens, H.A.M., Postma, D.S., Bischoff, R.: Protein tyrosine nitration: selectivity, physicochemical and biological consequences, denitration, and proteomics methods for the identification of tyrosine-nitrated proteins. J. Proteome Res.8, 3222-3238 (2009)

10. Taldone, F.S., Tummala, M., Goldstein, E.J., Ryzhov, V., Ravi, K., Black, S.M.: Studying the S-Nitrosylation of model peptides and eNOS protein by mass spectrometry. Nitric Oxide-Biol. Chem.13, 176-187 (2005)

11. Hao, G., Gross, S.S.: Electrospray tandem mass spectrometry analysis of S- and N-Nitrosopeptides: facile loss of $\mathrm{NO}$ and radical-induced fragmentation. J. Am. Soc. Mass Spectrom.17, 1725-1730 (2006)

12. Wang, Y., Liu, T., Wu, C., Li, H.: A strategy for direct identification of protein S-Nitrosylation sites by quadrupole time-of-flight mass spectrometry. J. Am. Soc. Mass Spectrom.19, 1353-1360 (2008)

13. Hao, G., Derakhshan, B., Shi, L., Campagne, F., Gross, S.S.: SNOSID, a proteomic method for identification of cysteine S-nitrosylation sites in complex protein mixtures. Proc. Natl. Acad. Sci. U.S.A.103, 1012-1017 (2006)

14. Forrester, M.T., Foster, M.W., Stamler, J.S.: Assessment and application of the biotin switch technique for examining protein S-nitrosylation under conditions of pharmacologically induced oxidative stress. J. Biol. Chem.282, 13977-13983 (2007)

15. Petersson, A.S., Steen, H., Kalume, D.E., Caidahl, K., Roepstorff, P.: Investigation of tyrosine nitration in proteins by mass spectrometry. $J$. Mass Spectrom.36, 616-625 (2001)

16. Seeley, K. W., Stevens, S. M., Jr.: Proceedings of the 58th ASMS Conference on Mass Spectrometry and Allied Topics. Salt Lake City (2010)

17. Zubarev, R.A., Kelleher, N.L., McLafferty, F.W.: Electron capture dissociation of multiply charged protein cations. A nonergodic process. J. Am. Chem. Soc.120, 3265-3266 (1998)

18. McLuckey, S.A., Goeringer, D.E.: Slow Heating Methods in Tandem Mass Spectrometry. J. Mass Spectrom.32, 461-474 (1997)

19. Syka, J.E.P., Coon, J.J., Schroeder, M.J., Shabanowitz, J., Hunt, D.F.: Peptide and protein sequence analysis by electron transfer dissociation mass spectrometry. Proc. Natl. Acad. Sci. USA101, 9528-9533 (2004)

20. Stensballe, A., Jensen, O.N., Olsen, J.V., Haselmann, K.F., Zubarev, R. A.: Electron capture dissociation of singly and multiply phosphorylated peptides. Rapid Commun. Mass Spectrom.14, 1793-1800 (2000)

21. Kelleher, R.L., Zubarev, R.A., Bush, K., Furie, B., Furie, B.C., McLafferty, F.W., Walsh, C.T.: Localization of labile posttranslational modifications by electron capture dissociation: the case of $\gamma$-carboxyglutamic acid. Anal. Chem.71, 4250-4253 (1999)

22. Mikesh, L.M., Ueberheide, B., Chi, A., Coon, J.J., Syka, J.E.P., Shabanowitz, J., Hunt, D.F.: The utility of ETD mass spectrometry in proteomic analysis. Biochem. Biophys. Acta1764, 1811-1822 (2006)

23. Hakansson, K., Cooper, H.J., Emmett, M.R., Costello, C.E., Marshall, A.G., Nilsson, C.L.: Electron capture dissociation and infrared multiphoton dissociation MS/MS of an N-glycosylated tryptic peptide to yield complementary sequence information. Anal. Chem.73, 4530-4536 (2001)

24. Mirgorodskaya, E., Roepstorff, P., Zubarev, R.A.: Localization of OGlycosylation sites in peptides by electron capture dissociation in a fourier transform mass spectrometer. Anal. Chem.71, 4431-4436 (1999)

25. Zhang, Q.B., Frolov, A., Tang, N., Hoffmann, R., van de Goor, T., Metz, T.O., Smith, R.D.: Application of electron transfer dissociation mass spectrometry in analyses of non-enzymatically glycated peptides. Rapid Commun. Mass Spectrom.21, 661-666 (2007)

26. Coon, J.J., Shabanowitz, J., Hunt, D.F., Syka, J.E.P.: Electron transfer dissociation of peptide anions. J. Am. Soc. Mass Spectrom.16, 880-882 (2005)

27. Huzarska, M., Ugalde, I., Kaplan, D. A., Hartmer, R., Easterling, M. L., Polfer, N. C.: Negative electron transfer dissociation of deprotonated phosphopeptide anions: choice of radical cation reagent and competition between electron and proton transfer. 82, 2873-2878 (2010)

28. Yoo, H. J., Zhuang, S., Wang, N., Hakansson, K.: Proceedings of the 58th ASMS Conference on Mass Spectrometry and Allied Topics. Salt Lake City, (May 2010)

29. Sohn, C.H., Chung, C.K., Yin, S., Ramachandran, P., Loo, J.A., Beauchamp, J.L.: Probing the mechanism of electron capture and 
electron transfer dissociation using tags with variable electron affinity. J. Am. Chem. Soc.131, 5444-5459 (2009)

30. Tureček, F.: Electron predators are hydrogen atom traps. Effects of Aryl groups on the $\mathrm{N}-\mathrm{C} \alpha$ bond dissociations of peptide radicals. J. Mass Spectrom. (2010, in press)

31. Jones, A.W., Mikhailov, V.A., Iniesta, J., Cooper, H.J.: Electron capture dissociation mass spectrometry of tyrosine nitrated peptides. J. Am. Soc. Mass Spectrom.21, 268-277 (2010)

32. Mikhailov, V.A., Iniesta, J., Cooper, H.J.: Top-down mass analysis of protein tyrosine nitration: comparison of electron capture dissociation with "Slow-Heating" tandem mass spectrometry methods. Anal. Chem. 82, 7283-7292 (2010)

33. Cook, S.L., Collin, O.L., Jackson, G.P.: Metastable atom-activated dissociation mass spectrometry: leucine/isoleucine differentiation and ring cleavage of proline residues. J. Mass Spectrom.44, 1211-1223 (2009)

34. Berkout, V.D.: Fragmentation of protonated peptide ions via interaction with metastable atoms. Anal. Chem.78, 3055-3061 (2006)

35. Misharin, A.S., Silivra, O.A., Kjeldsen, F., Zubarev, R.A.: Dissociation of peptide ions by fast atom bombardment in a quadrupole ion trap. Rapid Commun. Mass Spectrom.19, 2163-2171 (2005)

36. Berkout, V.D.: Fragmentation of singly protonated peptides via interaction with metastable rare gas atoms. Anal. Chem. 81, 725-731 (2009)

37. Berkout, V.D., Doroshenko, V.M.: Fragmentation of phosphorylated and singly charged peptide ions via interaction with metastable atoms. Int. J. Mass Spectrom. 278, 150-157 (2008)

38. Siska, P.E.: Molecular-beam studies of penning ionization. Rev. Mod. Phys. 65, 337-412 (1993)

39. Ohno, K., Imai, K., Harada, Y.: Variations in reactivity of lone-pair electrons due to intramolecular hydrogen-bonding as observed by penning ionization electron-spectroscopy. J. Am. Chem. Soc.107, 8078-8082 (1985)

40. Leymarie, N., Costello, C.E., O'Connor, P.B.: Electron capture dissociation initiates a free radical reaction cascade. J. Am. Chem. Soc.125, 8949-8958 (2003)

41. Sobczyk, M., Anusiewicz, W., Berdys-Kochanska, J., Sawicka, A., Skurski, P., Simons, J.: Coulomb-assisted dissociative electron attachment: application to a model peptide. J. Phys. Chem. A109, 250-258 (2005)

42. Syrstad, E.A., Turecek, F.: Toward a general mechanism of electron capture dissociation. J. Am. Soc. Mass Spectrom.16, 208-224 (2005)
43. Zubarev, R.A., Haselmann, K.F., Budnik, B., Kjeldsen, F., Jensen, F. Towards an understanding of the mechanism of electron-capture dissociation: a historical perspective and modern ideas. Eur. J. Mass Spectrom.8, 337-349 (2002)

44. Lee, S.J., Lee, J.R., Kim, Y.H., Park, Y.S., Park, S.I., Park, H.S., Kim, K.P.: Investigation of tyrosine nitration and nitrosylation of angiotensin II and bovine serum albumin with electrospray ionization mass spectrometry. Rapid Commun. Mass Spectrom.21, 2797-2804 (2007)

45. Kjeldsen, F., Haselmann, K.F., Sorensen, E.S., Zubarev, R.A.: Distinguishing of Ile/Leu amino acid residues in the PP3 protein by (Hot) electron capture dissociation in fourier transform ion cyclotron resonance mass spectrometry. Anal. Chem.75, 1267-1274 (2003)

46. Breuker, K., Oh, H.B., Cerda, B.A., Horn, D.M., McLafferty, F.W.: Hydrogen atom loss in electron-capture dissociation: a fourier transform-ion cyclotron resonance study with single isotopomeric ubiquitin ions. Eur. J. Mass Spectrom.8, 177-180 (2002)

47. Kaneko, R., Wada, Y.: Decomposition of protein nitrosothiols in matrix-assisted laser desorption/ionization and electrospray ionization mass spectrometry. J. Mass Spectrom.38, 526-530 (2003)

48. Mirza, U.A., Chait, B.T., Lander, H.M.: Monitoring reactions of NitricOxide with peptides and proteins by electrospray-ionization massspectrometry. J. Biol. Chem.270, 17185-17188 (1995)

49. Creese, A.J., Cooper, H.J.: The effect of phosphorylation on the electron capture dissociation of peptide ions. J. Am. Soc. Mass Spectrom.19, 1263-1274 (2008)

50. Kishimoto, N., Osada, Y., Ohno, K.: Penning ionization of amides by collision with $\mathrm{He}^{*}\left(2^{3} \mathrm{~s}\right)$ metastable atoms. J. Electron Spectrosc. Relat. Phenom.114, 183-190 (2001)

51. Ohno, K., Takano, S., Mase, K.: Penning ionization electron-spectroscopy of molecules containing the $\mathrm{C}=\mathrm{O}$ group - Aldehydes and Carboxylic-Acids. J. Phys. Chem.90, 2015-2019 (1986)

52. Budnik, B.A., Haselmann, K.F., Zubarev, R.A.: Electron detachment dissociation of peptide di-anions: an electron-hole recombination phenomenon. Chem. Phys. Lett.342, 299-302 (2001)

53. Kjeldsen, F., Silivra, O.A., Ivonin, I.A., Haselmann, K.F., Gorshkov, M., Zubarev, R.A.: C-Alpha-C Backbone fragmentation dominates in electron detachment dissociation of gas-phase polypeptide polyanions. Chem. Eur. J.11, 1803-1812 (2005)

54. Rumachik, N., McAlister, G.C., Coon, J.J.: Proceedings of the 58th ASMS Conference on Mass Spectrometry and Allied Topics. Salt lake City, (May 2010) 